Regular Paper

\title{
A Paper-Based Bio Fuel Cell Generating Power from the Biofilm of Bacillus Subtilis Bacteria
}

\author{
Dang Trang NGUYEN ${ }^{* 1}$, Kaname IWAI ${ }^{* 1}$, Toshihiro OZAWA ${ }^{* 1}$ and Kozo TAGUCHI ${ }^{* 1}\left(\mathrm{Mem}_{\text {.) }}\right.$ \\ In this research, we fabricated a low-cost, disposable, paper-based bio fuel cell that used an activated carbon-based \\ anode with the pre-inoculated biofilm of Bacillus Subtilis bacteria. The biofilm anode was dried for long-term storage \\ and the bio fuel cell could generate electricity on-demand within some minutes after adding a drop of tap water to the \\ dry biofilm anode. The anodic activated carbon substrate was treated by a plasma cleaner to increase hydrophilization \\ before inoculating bacterial biofilm. The fuel cell case was made of a normal paper filter. We integrated directly the \\ air-cathode and proton exchange membrane on the fuel cell case. The paper-based bio fuel cell can be potentially used \\ for micropower biosensor applications.
}

Keywords: bio fuel cell, MFC, Bacillus Subtilis, paper-based, biofilm.

(Received: 24 July 2018, Revised: 16 December 2018)

\section{Introduction}

Recently, renewable power generation method has been expected to solve the energy issues. Wind power generation, solar power generation and so forth are renewable energy generation methods. Although, these methods are low efficiency compared with thermal power generation and nuclear power generation, they are safe and environmentally-friendly. More recently, bio fuel cells have been receiving increasingly attention as new renewable energy. Microbial Fuel Cell (MFC) is a type of bio fuel cells, which produces electric power by decomposing bio fuel by microorganisms [1]. In other words, it can be useful in bio-waste treatment systems [2], [3].

Basically, there are two types of MFC configurations: two-chamber and single chamber [4]. A two chamber MFC consists of an anodic chamber and a cathodic chamber separated by a proton exchange membrane (PEM) and connected by an external electrical circuit. In the anodic chamber, the biofilm of a microorganism attached to the electrode breaks down organic matter to generate electrons and protons. The electrons are collected to the anode and move to the cathode through the external circuit. The protons in the anodic chamber move to the cathodic chamber through the PEM to close the circuit. In the cathodic chamber, a reduction reaction takes

\footnotetext{
Correspondence: K. TAGUCHI, Department of Electrical and Electronic Engineering, Ritsumeikan University, 1-1-1 Kusatsu, Shiga 525-8577, Japan email: taguchi@se.ritsumei.ac.jp

${ }^{* 1}$ Ritsumeikan University
}

place, where the protons and electrons combine with oxygen to generate water at the cathode. In addition, a single chamber MFC has the cathode exposed directly to the air and therefore eliminating the need of the cathodic chamber. The cathode is usually attached directly to the PEM. The single chamber MFC offers more compact, simpler, and lower cost than two-chamber MFC [5].

In MFC research, Shewanella and Geobacter bacteria are often used as microorganisms [5]. Shewanella and Geobacter are anaerobic bacteria. In this study, we aim at investigating the possibility of using air-dried biofilm of bacteria, which can be used in MFC to produce ondemand electricity in aerobic condition. Therefore, we used Bacillus Subtilis (BS) bacteria because it is aerobic, electrogenic [6], and can withstand unfavourable environments (dry and hot conditions) [7]. To date, there were few researches studying about utilizing BS bacteria for MFC [8].

In this study, we developed a disposable MFC, which used dry biofilm of BS bacteria inoculated directly on a conductive anode made of activated carbon paper. For the sake of cost advantage and flexibility, the MFC was fabricated on a single paper filter. We coated carbon nanotube (CNT) mixed with potassium ferricyanide on a side of the paper filter to make a dry air-cathode. While, the other side of the paper filter was coated by hydrophobic spray and functioned as a low-cost paper-based PEM. That unique design provides the cost-effective, portable, and disposable MFC.

\section{Method and materials}

\subsection{Experimental method}




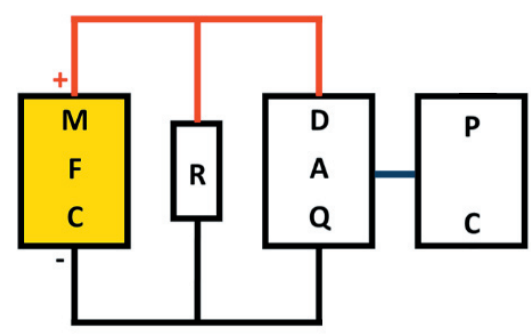

Fig. 1 Measurement setup.

The experimental setup is shown in Fig. 1. the MFC was discharged by an external resistor $(R)$ of $5 \mathrm{k} \Omega$. A data acquisition system (DAQ, National Instruments, NI USB-6210) connected to a customized LabVIEW interface on a computer (PC) was used to monitor the voltage across the external resistor. After injecting tap water into the dry biofilm anode, the voltage over resistor was recorded every $10 \mathrm{~s}$ for about $40 \mathrm{~min}$. Each experiment was conducted three times in the same conditions and the average result was used in this paper.

\subsection{MFC design and materials}

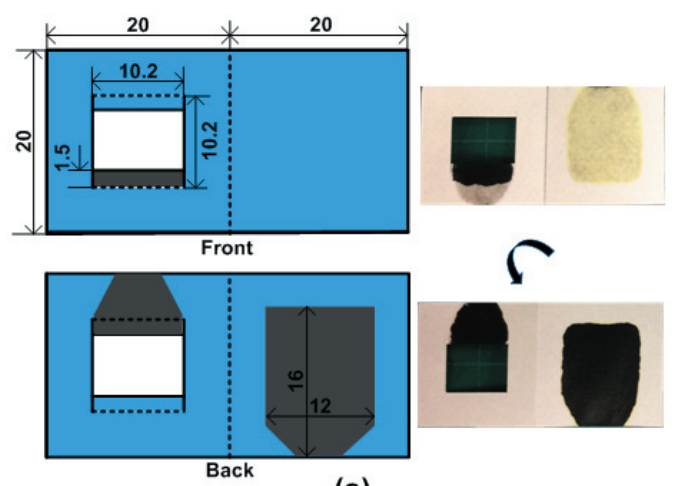

(a)
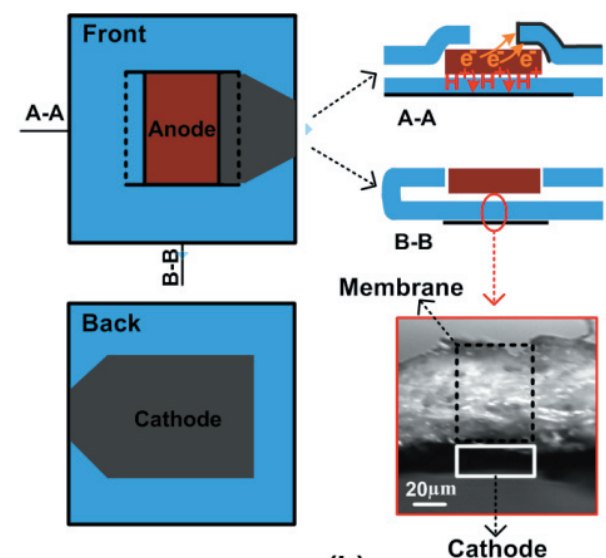

(b)

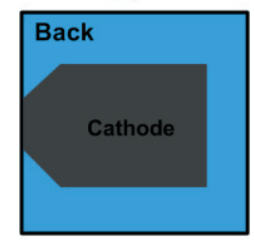

Fig. 2 The design of the paper-based MFC. (a) Detail diagrams of the front and back sides of the MFC case and its photo images. (b) The MFC case after folding, the $3 \mathrm{D}$ cross-sections, and the microscope photo of the integrated membrane cathode.

The detail design of the proposed paper-based MFC is shown in Fig. 2. We adopted single chamber configuration for our MFC. It was fabricated based on a single paper filter (Advantec \#6, thickness of $0.1 \mathrm{~cm}$ ).

Fig. 2 (a) shows the design and photos of the front and back sides of the MFC case. A setup place for the biofilm anode was cut at the centre of the top part with double flaps at two opposite edges to hold and keep the anode attached to the membrane when assembling the MFC. Electrical contact for the anode were made by coating carbon nanotube (CNT) (multi-walled CNT dispersion coating liquid N7006L, KJ Specialty Paper) on both front and back sides of one flap. The cathode was fabricated on the back side of the MFC case by coating CNT mixed with potassium ferricyanide $(3 \mathrm{ml} 0.3 \mathrm{M}$ potassium ferricyanide mixed in $20 \mathrm{ml} \mathrm{CNT}$ ) then followed by drying in a drying oven at $50{ }^{\circ} \mathrm{C}$ for $10 \mathrm{~min}$. The front side served as a paper-based PEM. We named this unique design "integrated membrane cathode". The MFC case was spray by hydrophobic solution (Water Proof Spray) to prevent solution leaking to the case during experiments and to make the effective paper-based PEM. The MFC was assembled by folding the MFC case along the folding line (dashed line) at the middle (Fig. 2 (a)). Adhesive or clip can be used for clamping the paper-based MFC when conducting experiment.

Fig. 2 (b) shows the schematic diagrams of the MFC case after folding and the 3D cross-sections. It also shows the cross-section of the integrated membrane cathode observed with a microscope. The integrated membrane cathode had a smooth vertical continuous transition from the coated cathode (thickness of about $20 \mu \mathrm{m}$ ) to the membrane (thickness of about $80 \mu \mathrm{m}$ ). The continuity enables high proton exchange efficiency, as a result, decreasing the internal resistance of the MFC [9].

The assembled MFC with the biofilm anode had compact size of about $2 \mathrm{~cm} \times 2 \mathrm{~cm} \times 0.06 \mathrm{~cm}$ and dry-weight of about $150 \mathrm{mg}$.

Table 1 LB medium composition

\begin{tabular}{|l|c|}
\hline \multicolumn{1}{|c|}{ Composition } & Amount (g/L in water) \\
\hline Tryptone & 10 \\
\hline Yeast extract & 5 \\
\hline $\mathrm{NaCl}$ & 10 \\
\hline $\mathrm{NaOH}$ & For adjustment of $\mathrm{pH}=7.0$ \\
\hline
\end{tabular}




\subsection{Biofilm anode preparation}

In this research, we utilized conductive material, activated carbon paper, to make the anode. The anode is pre-inoculated the biofilm of BS cells, as a result, all bacterial cells could contribute electrons to the electrode and could maximize the power generation. BS cells were cultured from freeze-dried stock of Bacillus subtilis var. natto by inoculating in LB medium (Table 1) in a shaking incubator at $40{ }^{\circ} \mathrm{C}$. Activated carbon paper (RCA-01, AZUMI FILTER PAPER CO., LTD) (size of $1 \mathrm{~cm} \mathrm{x} 1$ $\mathrm{cm} \times 0.04 \mathrm{~cm}$ ) was first treated by a plasma cleaner (Filgen UV253-OZ) for 12 hours to improve hydrophilization then immersed in the bacterial culture medium to form biofilm of BS cells. After $48 \mathrm{~h}$ of cultivation, the inoculated biofilm anodes were air-dried at $40{ }^{\circ} \mathrm{C}$ and $30 \%$ relative humidity for $24 \mathrm{~h}$, then stored in zip-lock plastic bags at room temperature $\left(25^{\circ} \mathrm{C}\right)$.

\section{Results and discussion}

In this research, we aimed at using sustainable carbon-based materials for the anode. To select the effective material for the anode, we initially utilized both carbon paper and activated carbon paper.

On the cathode side, we also investigated the effectiveness of the proposed potassium ferricyanide loaded cathode by comparing the performance of the MFC equipped with the cathode made by coating CNT solution with and without mixing with potassium ferricyanide, respectively.

\subsection{Biofilm observation}
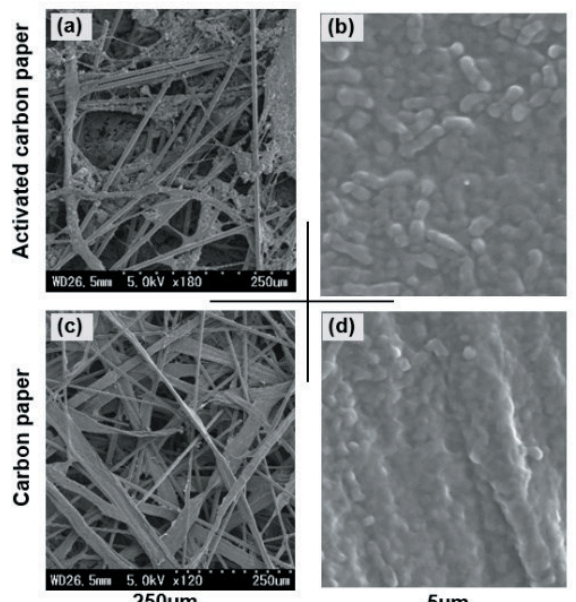

Fig. 3 SEM images of the biofilm anodes made of activated carbon paper $(a, b)$ and carbon paper $(c, d)$ at different magnification.
We observed the surface of the biofilm anode made of activated carbon paper and carbon paper by a scanning electron microscope (SEM, S-4300 Hitachi). As shown in Fig. 3 (a) and (c), the tomography of the activated carbon paper shows higher degree of porosity than that of the carbon paper. Fig. 3 (b) and (d) display the biofilm of BS bacteria on the surface of activated carbon paper anode and carbon paper anode, respectively. The BS cells are rod-shaped with the length of 0.5-2 $\mu \mathrm{m}$. In addition, the biofilm of bacterial cells was grown not only on the surface but also deep inside the anode because of its porous $3 \mathrm{D}$ structure.

\subsection{Control experiments}

We conducted some control experiments to assess the role of the bacterial biofilm, anodic material, and cathodic material on the output of the MFC.

Initially, we did an experiment to confirm that bacterial biofilm was the main actor in electricity generation. Two MFCs using activated carbon paper-based anodes with and without BS bacterial biofilm, respectively, were activated by $30 \mu \mathrm{l}$ tap water. The anode without bacterial biofilm was made by using the activated carbon paper directly without inoculating bacterial cells. In this experiment, the cathode was made of CNT mixed with potassium ferricyanide. Fig. 4 shows the output of the MFCs. When absence of bacteria, the output was minus polarity and negligible. The output is believed to be due to complex chemical oxidation reactions of activated carbon loaded on the anode. In contrast, when there was the presence of the bacterial biofilm, much higher output was observed. From this experiment, we could confirm that bacterial cells were the main actor in the power generation of the MFCs.

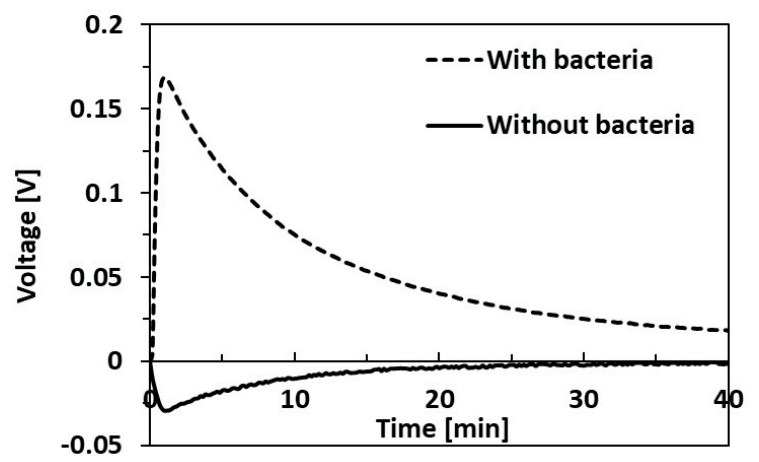

Fig. 4 Discharging voltage output of the MFCs using the anode inoculated with the bacterial biofilm and the anode without bacteria. 
The explanation of the output behaviour is that as water added to the dry biofilm anode, firm connection between the anode and the membrane is quickly established by the water. Consequently, protons migrate along pathways through the membrane to the cathode while electrons go to the cathode through the external circuit to complete the electrical circuit. Therefore, the peak voltage was established quickly after adding water. However, the output gradually decreased because the MFC was discharged by a $5 \mathrm{k} \Omega$ resistor

Furthermore, we considered anodic material, which has crucial impact on the output of MFC [10]. To determine an effective material for the anode, carbon paper and activated carbon paper were tested. Carbon paperbased anode and activated carbon paper-based anode with the same size and thickness were prepared following the method described in the previous section. Fig. 5 shows the outputs of the experiment using the two anodic materials. The cathode was made of CNT mixed with potassium ferricyanide in this experiment. The activated carbon paper-based biofilm anode generated much higher output than that of the carbon paper-based anode. This result might be attributed to higher degree of micro-porosity and higher adsorption capacity of the activated carbon paper [11] compared with carbon paper. Therefore, activated carbon paper enables better electron transfer from bacterial cells. Also, this analysis is supported by the tomography of these materials observed by SEM as shown in Fig. 3. Based on this result, we decided to use activated carbon paper in lieu of carbon paper for the anode. Finally, the effectiveness of potassium ferricyanide added to the cathode was considered. Potassium ferricyanide has been used as an effective electron acceptor in MFC research [12].

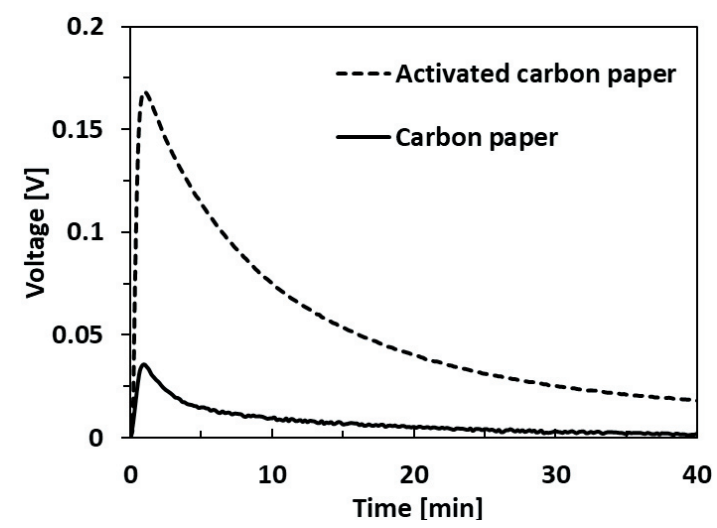

Fig. 5 The effect of anodic materials on the performance of the MFC (two biofilm anodes made of carbon paper and activated carbon paper, respectively).

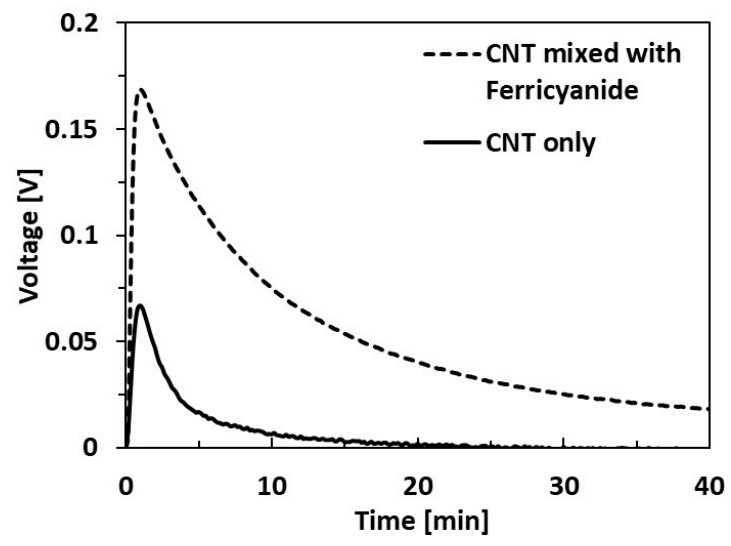

Fig. 6 The effectiveness of Potassium Ferricyanide in the cathode on the performance of the MFC.

However, it is usually used in aquatic form. For the sake of convenience for practical uses, we proposed the dry integrated membrane cathode with potassium ferricyanide preloaded. This practical preparation method is especially suitable for disposable applications. Fig. 6 shows the improvement when using the dry ferricyanide-preloaded cathode compared with the case without ferricyanide (CNT-only cathode). With identical activated carbon paper-based biofilm anodes, the effectiveness of our method of using dry ferricyanide-preloaded cathode was clearly observed with much higher peak voltage and much longer discharging time. The CNT-only cathode used oxygen in the air as a final electron acceptor. However, oxygen is ineffective in electron reduction reaction [12]. Therefore, CNT-only cathode generated much lower electricity compared with the ferricyanide-preloaded cathode.

\subsection{MFC performance}

In this work, we developed the disposable MFC, which used the dry biofilm of BS bacteria inoculated directly on the anode. We expected that idle bacterial cells in the dry biofilm could be activated by mere tap water and the dry biofilm could generate electricity after longterm storage. Because of limited time available for this research, we were only able to investigate the electricity generation ability of the dry biofilm anodes stored up to one month.

Fig. 7 shows the output voltage (discharged by a 5 $\mathrm{k} \Omega$ resistor) from the MFCs using 0 -week (after drying), 2-week, and 4-week stored biofilm anodes, respectively. The biofilm anodes after drying generated the highest maximum voltage. The output shows small decrease with the biofilm anodes stored for 2 weeks. However, there was a significant decline in the output of the MFCs with 
the biofilm anodes stored for 4 weeks. This was attributed to the effect of long-time storage on the deterioration of the dry bacterial biofilm. From the experimental data, we can logically anticipate that the output will decrease along longer storage time with accelerated rate to finally approach the similar output of the case without bacteria (as shown in Fig. 4). It may take as long as many months of storage until all bacterial cells die out because BS bacteria is renown with outstanding survival strategies in unfavourable conditions [13]. In addition, the power density of the MFC was also measured. Fig. 8 shows the maximum output voltage and the power density measured based on the maximum values obtained at given discharging resistors of $500 \mathrm{k} \Omega, 10 \mathrm{k} \Omega, 5 \mathrm{k} \Omega, 2.7 \mathrm{k} \Omega, 1 \mathrm{k} \Omega$, $0.5 \mathrm{k} \Omega$. From the polarization curve, it can be confirmed that the highest power density of $8.3 \mu \mathrm{W} / \mathrm{cm}^{2}$ was obtained at $2.7 \mathrm{k} \Omega$.

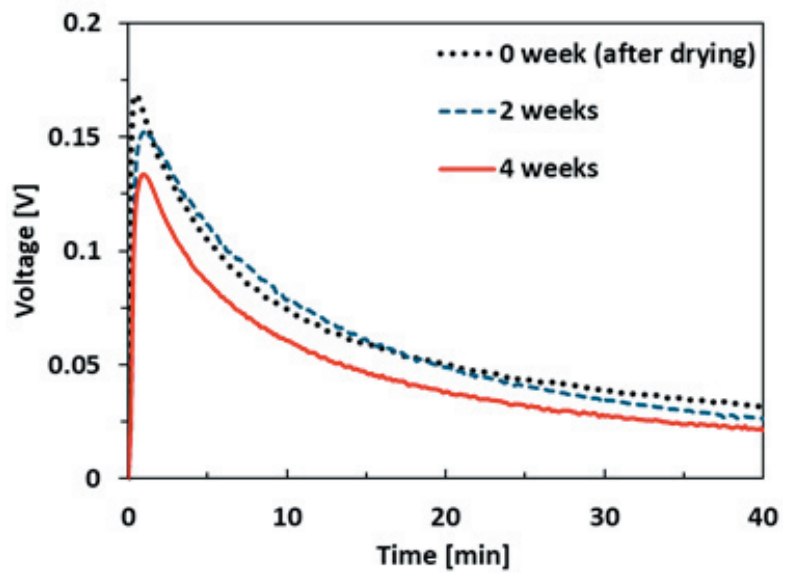

Fig. 7 Discharging voltage output of the MFCs using air-dried biofilm anodes at different storage time.

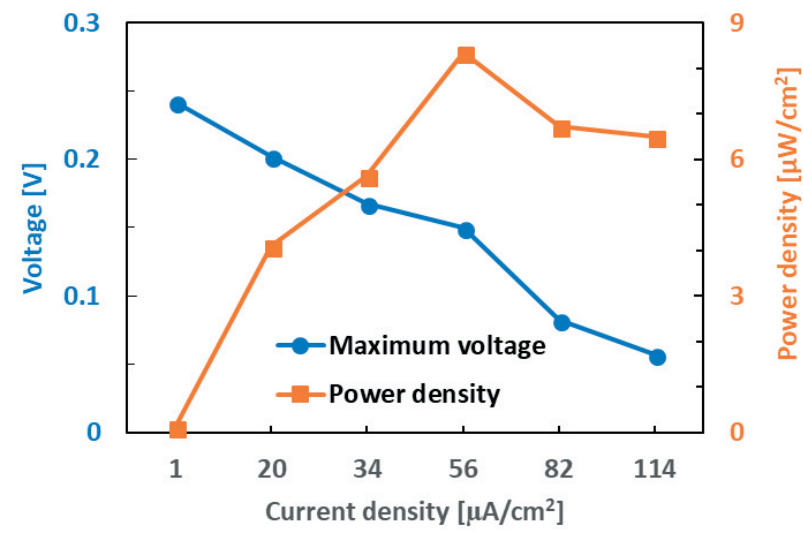

Fig. 8 The maximum discharging voltage and power density measured at some given external resistors of $500 \mathrm{k} \Omega, 10 \mathrm{k} \Omega, 5 \mathrm{k} \Omega, 2.7 \mathrm{k} \Omega, 1 \mathrm{k} \Omega, 0.5 \mathrm{k} \Omega$.
It has been proved that the internal resistance of a device is estimated to be equal to the value of the discharging resistor at which the maximum power is achieved [14]. Therefore, the internal resistance of our MFC was estimated about $2.7 \mathrm{k} \Omega$, which was significantly lower compared with other reported paper-based MFCs with hundred $\mathrm{k} \Omega$ level [15]. The low internal resistance of our MFC was attributed to the innovation of the integrated membrane cathode, which enabled smooth and firm vertical continuity between the cathode and the paper-based PEM.

\subsection{Recycle experiment of biofilm anode}

The MFC presented here is aimed for disposable application only (one-time-use application). With that purpose in mind, we have designed and fabricated the MFC based on low-cost materials and disposable solutions.

However, to further discuss the paper-based MFC characteristics, we also conducted a recycle experiment with three cycles of using the same biofilm anode. After each cycle, we left the biofilm anode at room temperature for $12 \mathrm{~h}$ then conducted the next discharging cycle. Because the cathode was preloaded potassium ferricyanide, which transformed to potassium ferrocyanide after discharging and lost the electron-acceptor ability [12], after each cycle a new MFC case (new cathode) was used. The experimental data is shown in Fig. 9. Even though, we have used a new MFC case for each cycle, it showed significant decrease in the whole time-span of the output after each cycle. This was due to bacterial biofilm in the anode did not have favorable condition for growing and proliferation after activated by mere water. Therefore, it could not significantly regenerate energy after each cycle.

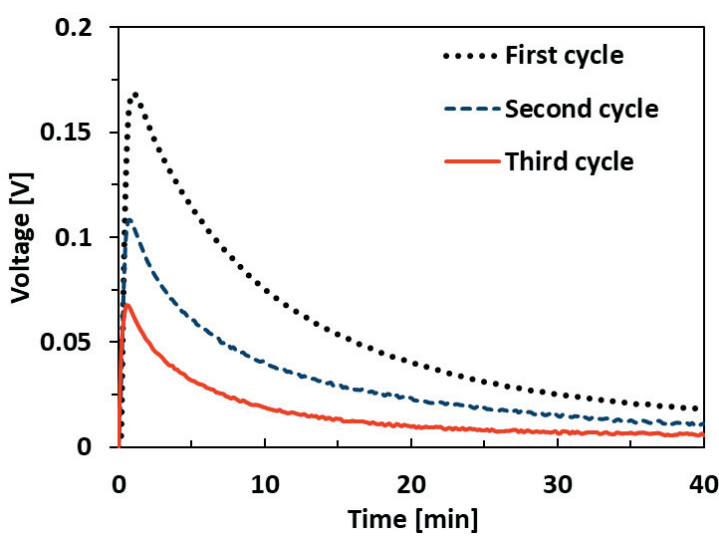

Fig. 9 The recycle experiment of the biofilm anode. 


\section{Conclusion}

In conclusion, we fabricated a disposable paper-based MFC. The MFC case was fabricated with a paper-based membrane with an integrated air-cathode. The anode was based on an activated carbon paper preloaded the biofilm of Bacillus Subtilis bacteria. This study focused on demonstrating the concept of utilizing dry bacterial biofilms in the MFCs, which could provide on-demand electricity generation. Experimental results showed that the dry biofilm anodes could still generate electricity after 4 weeks of storage.

\section{Acknowledgment}

A part of this research was supported by AZUMI FILTERPAPER CO., Ltd.

\section{References}

[1] M. Rahimnejad, A. Adhami, S. Darvari, A. Zirepour, and S.-E. Oh, "Microbial fuel cell as new technology for bioelectricity generation: A review," Alexandria Eng. J., Vol. 54, No. 3, pp. 745-756, 2015.

[2] D. R. Lovley, "Microbial fuel cells: novel microbial physiologies and engineering approaches," Current Opinion in Biotechnology, Vol. 17, No. 3. pp. 327-332, 2006.

[3] K. Rabaey and W. Verstraete, "Microbial fuel cells: Novel biotechnology for energy generation," Trends in Biotechnology, Vol. 23, No. 6. pp. 291-298, 2005.

[4] A. Rinaldi, B. Mecheri, V. Garavaglia, S. Licoccia, P. Di Nardo, and E. Traversa, "Engineering materials and biology to boost performance of microbial fuel cells: a critical review," Energy Environ. Sci., Vol. 1, No. 4, pp. 417, 2008.

[5] M. H. Osman, A. A. Shah, and F. C. Walsh, "Recent progress and continuing challenges in bio-fuel cells. Part I: Enzymatic cells," Biosensors and Bioelectronics, Vol. 26, No. 7. pp. 3087-3102, 2011.

[6] V. R. Nimje, C.-Y. Chen, C.-C. Chen, J.-S. Jean, A. S. Reddy, C.-W. Fan, K.-Y. Pan, H.-T. Liu, and J.-L. Chen, "Stable and high energy generation by a strain of Bacillus subtilis in a microbial fuel cell," J. Power Sources, Vol. 190, No. 2, pp. 258-263, 2009.

[7] M. Morikawa, "Beneficial biofilm formation by industrial bacteria Bacillus subtilis and related species," J. Biosci. Bioeng., Vol. 101, No. 1, pp. 1-8, 2006.

[8] H. Hassan, L. Schulte-Illingheim, B. Jin, and S. Dai, "Degradation of 2,4-Dichlorophenol by Bacillus Subtilis with Concurrent Electricity Generation in Microbial Fuel Cell," in Procedia Engineering, Vol. 148, pp. 370-377, 2016.

[9] H. Lee and S. Choi, "An origami paper-based bacteriapowered battery with an air-cathod," in 2015 Transducers 2015 18th International Conference on Solid-State Sensors, Actuators and Microsystems, TRANSDUCERS 2015, pp. 1009-1012, 2015.

[10]M. Ghasemi, W. R. W. Daud, N. Mokhtarian, A. Mayahi, M. Ismail, F. Anisi, M. Sedighi, and J. Alam, "The effect of nitric acid, ethylenediamine, and diethanolamine modified polyaniline nanoparticles anode electrode in a microbial fuel cell," Int. J. Hydrogen Energy, Vol. 38, No. 22, pp. 9525-9532, 2013.

[11]T. Lee, C.-H. Ooi, R. Othman, F.-Y. Yeoh, F.-Y. Yeoh, T. Lee, C.-H. Ooi, and R. Othman, "Activated Carbon Fiber the Hybrid of Carbon Fiber and Activated Carbon," Rev. Adv. Mater. Sci, Vol. 36, pp. 118-136, 2014.

[12]B. E. Logan, B. Hamelers, R. Rozendal, U. Schröder, J. Keller, S. Freguia, P. Aelterman, W. Verstraete, and K. Rabaey, "Microbial fuel cells: Methodology and technology," Environmental Science and Technology, Vol. 40, No. 17. pp. 5181-5192, 2006.

[13]M. Sakil Munna, J. Tahera, M. Mohibul Hassan Afrad, I. T. Nur, and R. Noor, "Survival of Bacillus spp. SUBB01 at high temperatures and a preliminary assessment of its ability to protect heat-stressed Escherichia coli cells Microbiology," BMC Res. Notes, Vol. 8, pp. 637-641, 2015.

[14]Y. Fan, E. Sharbrough, and H. Liu, "Quantification of the internal resistance distribution of microbial fuel cells.," Environ. Sci. Technol., Vol. 42, No. xx, pp. 8101-7, 2008.

[15]H. Lee and S. Choi, "An origami paper-based bacteriapowered battery," Nano Energy, Vol. 15, pp. 549-557, Jul. 2015. 